Check for updates

Cite this: RSC Adv., 2021, 11, 8356

\title{
Rhodium(III) catalyzed olefination and deuteration of tetrahydrocarbazole $\uparrow$
}

\author{
Wan Peng, Qiaohong Liu, Fucheng Yin, Cunjian Shi, Limei Ji, Lailiang Qu, \\ Cheng Wang, Heng Luo, Lingyi Kong (D) and Xiaobing Wang (D)
}

The rhodium-catalyzed olefination and deuteration of tetrahydrocarbazoles in water with the aid of an N,Ndimethylcarbamoyl-protected group is presented. This olefination method features a broad substrate scope, good functional-group tolerance, and high efficiency in water. Practical applications of the protocol are illustrated by the synthesis of various evodiamine derivatives. As such, this environmentally friendly approach to directly modify natural products will attract much attention in academic and industrial research.

Received 11th January 2021

Accepted 25th January 2021

DOI: $10.1039 / \mathrm{d} 1 \mathrm{ra00236h}$

rsc.li/rsc-advances

The regioselective modification of natural products via the

\section{Introduction}

$\mathrm{C}-\mathrm{H}$ functionalization strategies, which emerged as an increasingly powerful synthetic method, can functionalize the inactivated $\mathrm{C}-\mathrm{H}$ bond or $\mathrm{C}-\mathrm{C}$ bond directly, but provide high reaction efficiency and atom economy. ${ }^{1}$ Rhodium catalysts have become quite popular in this field due to their high efficiency, good regioselectivity, and wide functional group tolerance. ${ }^{2}$ The tetrahydrocarbazole framework is a common subunit in many bioactive compounds, and serves as the core to a wide variety of natural products, bioactive molecules and pharmaceuticals (Scheme 1a). ${ }^{3}$ Tetrahydrocarbazole is one type of indole in which the $\mathrm{C} 2$ and $\mathrm{C} 3$ position were fused with a six-membered ring. Few studies on the $\mathrm{C}-\mathrm{H}$ functionalization of tetrahydrocarbazole were reported, such as $N, N$-dimethylcarbamoylprotected tetrahydrocarbazoles undergo directly oxidative to exclusively provide products from $\mathrm{C}\left(\mathrm{sp}^{3}\right)-\mathrm{H}$ oxidation (2014). ${ }^{4}$ However, indoles and indolines mediated by organocatalysts and transition metals have made fruitful and important progress. ${ }^{5}$ For instance, alkenylation, ${ }^{6}$ arylation, ${ }^{7}$ alkylation ${ }^{8}$ and others $^{9}$ of indoles and indolines at the $\mathrm{C} 7$ position have been described. The Oestreich group reported the palladium(II)catalyzed arylation of 2,3-substituted indolines (Scheme 1b). ${ }^{\mathbf{1 0}}$ These results led us to explore whether this C8functionalization strategy can be applied in tetrahydrocarbazoles.

\footnotetext{
Jiangsu Key Laboratory of Bioactive Natural Product Research, State Key Laboratory of Natural Medicines, School of Traditional Chinese Pharmacy, China Pharmaceutical University, 24 Tong Jia Xiang, Nanjing 210009, People's Republic of China. E-mail: xbwang@cpu.edu.cn; cpu_lykong@126.com; Fax: +86-25-83271405; Tel: +86-2583271405

† Electronic supplementary information (ESI) available: Experimental procedures, compound characterization, and copies of ${ }^{1} \mathrm{H}$ and ${ }^{13} \mathrm{C}$ NMR spectra. CCDC 2025858. For ESI and crystallographic data in CIF or other electronic format see DOI: $10.1039 / \mathrm{d} 1 \mathrm{ra} 00236 \mathrm{~h}$
} metal-catalyzed $\mathrm{C}-\mathrm{H}$ bond activation strategy is difficult, ${ }^{11}$ we demonstrated an efficient rhodium-catalyzed synthetic route for regioselective olefination of tetrahydrocarbazole in water. The present protocol using water as the solvent was compatible with a wide range of substituents on the tetrahydrocarbazole substrate. Furthermore, olefinated products could also be generated in a moderate yield at a lower reaction temperature in the developed system. It was also found that regioselective alkenylation of tetrahydrocarbazole derivatives followed by onepot subsequent deprotection provides the desired product in good yield. In addition, synthetic applications of this novel alkenylation method were further demonstrated in an efficient modification of evodiamine.

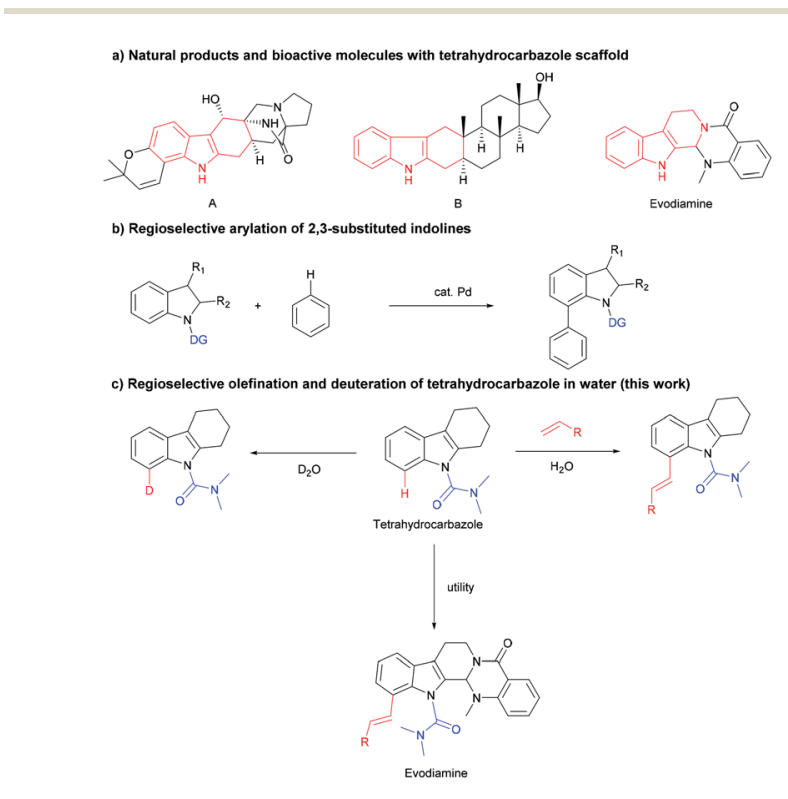

Scheme 1 Outline of the research. 
On the other hand, isotopic labelling is of high significance for their utility, e.g. for investigating reaction mechanisms, ${ }^{12}$ exploring the ADMET properties of existing drug candidates, ${ }^{13}$ or in nuclear magnetic resonance spectroscopy ${ }^{\mathbf{1 4}}$ and mass spectrometry. ${ }^{15}$ Since the FDA approved deutetrabenazine, which is the first deuterated drug in $2017,{ }^{16}$ deuterium has received unprecedented widespread attention. Versatile applications of deuterium-labelled compounds demand effective synthetic methods to regioselectively introduce deuterium atoms at specific positions. Hydrogen isotope exchange (HIE) assisted by metal-catalyzed $\mathrm{C}-\mathrm{H}$ activation has become a widely utilized and elegant method for synthesizing isotopically labelled compounds, allowing direct and selective late-stage incorporation of deuterium or tritium $\left({ }^{2} \mathrm{H}\right.$ or $\left.{ }^{3} \mathrm{H}\right) \cdot{ }^{17}$ Inspired by our above developed rhodium-catalyzed regio-olefination, we have also successfully achieved deuteration labelling of tetrahydrocarbazole with $\mathrm{D}_{2} \mathrm{O}$, which serves as an economical deuterium source and solvent in this reaction.

\section{Results and discussion}

Initially, we started this idea using $N, N$-dimethylcarbamoylprotected $^{\mathbf{1 8 a}}$ tetrahydrocarbazole $\mathbf{1 a}$ and ethyl acrylate $\mathbf{2}$ as the template substrates. To our delight, the desired olefinated product 3a was obtained in good yield (75\%) under the

Table 1 Optimization of olefination conditions ${ }^{a}$

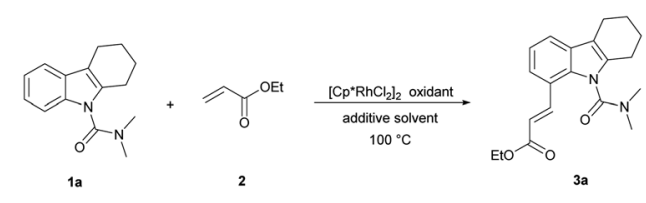

\begin{tabular}{|c|c|c|c|c|}
\hline Entry & Oxidant & Solvent & Additive & Yield $^{b}(\%)$ \\
\hline 1 & $\mathrm{Cu}(\mathrm{OAc})_{2}$ & DCE & $\mathrm{AgSbF}_{6}$ & 75 \\
\hline 2 & $\mathrm{AgOAc}$ & DCE & $\mathrm{AgSbF}_{6}$ & Trace \\
\hline 3 & $\mathrm{BQ}$ & DCE & $\mathrm{AgSbF}_{6}$ & Trace \\
\hline 4 & $\mathrm{PhI}(\mathrm{OAc})_{2}$ & DCE & $\mathrm{AgSbF}_{6}$ & - \\
\hline 5 & $\mathrm{Ag}_{2} \mathrm{CO}_{3}$ & DCE & $\mathrm{AgSbF}_{6}$ & 28 \\
\hline 6 & $\mathrm{Cu}(\mathrm{OAc})_{2}$ & Dioxane & $\mathrm{AgSbF}_{6}$ & 40 \\
\hline 7 & $\mathrm{Cu}(\mathrm{OAc})_{2}$ & $\mathrm{PhCF}_{3}$ & $\mathrm{AgSbF}_{6}$ & 61 \\
\hline 8 & $\mathrm{Cu}(\mathrm{OAc})_{2}$ & $\mathrm{CH}_{3} \mathrm{CN}$ & $\mathrm{AgSbF}_{6}$ & - \\
\hline 9 & $\mathrm{Cu}(\mathrm{OAc})_{2}$ & $t-\mathrm{AmOH}$ & $\mathrm{AgSbF}_{6}$ & 17 \\
\hline 10 & $\mathrm{Cu}(\mathrm{OAc})_{2}$ & DCE & $\mathrm{AgNTf}_{2}$ & 86 \\
\hline $11^{c}$ & $\mathrm{Cu}(\mathrm{OAc})_{2}$ & DCE & $\operatorname{AgNTf}_{2}$ & 93 \\
\hline $12^{c}$ & $\mathrm{Cu}(\mathrm{OAc})_{2}$ & $\mathrm{H}_{2} \mathrm{O}$ & $\operatorname{AgNTf}_{2}$ & 90 \\
\hline $13^{d}$ & $\mathrm{Cu}(\mathrm{OAc})_{2}$ & $\mathrm{H}_{2} \mathrm{O}$ & $\mathrm{AgNTf}_{2}$ & 86 \\
\hline $14^{d, e}$ & $\mathrm{Cu}(\mathrm{OAc})_{2}$ & $\mathrm{H}_{2} \mathrm{O}$ & AgNTf $_{2}$ & 78 \\
\hline 15 & - & $\mathrm{H}_{2} \mathrm{O}$ & $\mathrm{AgNTf}_{2}$ & 10 \\
\hline 16 & $\mathrm{Cu}(\mathrm{OAc})_{2}$ & $\mathrm{H}_{2} \mathrm{O}$ & - & Trace \\
\hline
\end{tabular}

${ }^{a} \mathbf{1 a}\left(0.1 \text { mmol, } 1 \text { equiv.), } 2 \text { (5 equiv.), [Cp* } \mathrm{RhCl}_{2}\right]_{2}$ (5 mol\%), $\mathrm{AgSbF}_{6}$ (20 mol\%), $\mathrm{Cu}(\mathrm{OAc})_{2}$ (3 equiv.), solvent $(1.0 \mathrm{~mL}), 100{ }^{\circ} \mathrm{C}, 12 \mathrm{~h} .{ }^{b}$ Data were obtained by ${ }^{1} \mathrm{H}$ NMR analysis with $\mathrm{CH}_{2} \mathrm{Br}_{2}$ as reference. ${ }^{c} 80{ }^{\circ} \mathrm{C}$. ${ }^{d}$ 1a $(0.1 \mathrm{mmol}, 1 \text { equiv.), } 2 \text { (2 equiv.), [Cp*RhCl }]_{2}$ (4 mol\%), $\mathrm{AgSbF}_{6}$ (20 mol\%), $\mathrm{Cu}(\mathrm{OAc})_{2}$ (2 equiv.), $\mathrm{H}_{2} \mathrm{O}(1.0 \mathrm{~mL}), 80{ }^{\circ} \mathrm{C}, 12$ h. ${ }^{e} 60{ }^{\circ} \mathrm{C}$. $\mathrm{DCE}=$ dichloroethane, $\mathrm{BQ}=$ benzoquinone, $\mathrm{PhCF}_{3}=$ benzotrifluoride, $\mathrm{CH}_{3} \mathrm{CN}=$ acetonitrile, $t-\mathrm{AmOH}=2$-methyl-2-butanol. conditions of $5 \mathrm{~mol} \%\left[\mathrm{Cp}^{*} \mathrm{RhCl}_{2}\right]_{2}, 20 \mathrm{~mol}^{2} \mathrm{AgSbF}_{6}$, and 3 equiv. of $\mathrm{Cu}(\mathrm{OAc})_{2}$ in DCE at $100{ }^{\circ} \mathrm{C}$ for $12 \mathrm{~h}$ (Table 1 , entry 1 ). Then, through evaluating different types of oxidants, $\mathrm{Cu}(\mathrm{OAc})_{2}$ was found to be superior to the rest (entries 2-5). ${ }^{18 a}$ Thereafter, further screening of reaction solvents revealed that DCE showed the best performance in this reaction using $\mathrm{AgSbF}_{6}$ as an additive (entries 6-9). Addition of $\mathrm{AgNTf}_{2}$ in place of $\mathrm{AgSbF}_{6}$ could improve the yield of $\mathbf{3 a}$ (entry 10). ${ }^{\mathbf{1 8 b}}$ Further shortening or extending the reaction time offered no improvement to the yield (Table S1 in the ESI $\dagger$ ). Moreover, decreasing the reaction temperature to $80{ }^{\circ} \mathrm{C}$ was beneficial to the olefination, and the product 3a was obtained in 93\% yield (entry 11 and Table S2 $\dagger$ ). To our delight, we accidentally found that the reaction proceeded smoothly in water without obvious decrease in the yield (entry 12). Considering the cost and environmental factor, we decided to employ the reaction using water as the solvent. Lowering the amount of catalyst, oxidant, additive and ethyl acrylate (Tables S3-S5 $\dagger$ ), we got the final optimized reaction conditions (entry 13). In addition, we also found that this reaction could proceed and provided the desired alkenylated product $3 \mathrm{a}$ in moderate yield (78\%) when the temperature was decreased to $60{ }^{\circ} \mathrm{C}$ (entry 14). 3a was observed with a yield of $10 \%$ when the reaction was carried out without an oxidant (entry 15). The reaction hardly happened without an additive (entry 16). These results showed that the oxidant and additive had crucial roles in this olefination.

With the optimal reaction conditions established, we next explored olefination with a variety of substituted tetrahydrocarbazoles (Table 2). For C6-substituted substrates, moderate to good yields were obtained with both electrondonating $(\mathbf{3 b}, \mathbf{3 c})$ and electron-withdrawing groups (3d-3h) compared to C5-substituted substrates (3i, 3j) and C7substituted substrates $(\mathbf{3 k - 3 m})$. It is noteworthy that the halogen groups such as $\mathrm{F}(\mathbf{3 e}, \mathbf{3 n})$ and $\mathrm{Cl}(\mathbf{3 f})$ performed well in C8-olefination. In comparison with substrates bearing electrondonating groups $\left(-\mathrm{CH}_{3},-\mathrm{C}\left(\mathrm{CH}_{3}\right)_{3}\right)$, those bearing electronwithdrawing groups $(-\mathrm{F},-\mathrm{Cl}$ and $-\mathrm{Br})$ decreased the overall yields, which might imply an electrophilic activation pattern. We were pleased to find that tetrahydrocarbazoles containing a methyl group at the six-membered ring were olefinated in good yields, with good selectivity (3o-3t) and did not affect the efficiency of this process. The size of the aliphatic ring was well tolerated (3u). The presence of an additional piperidine ring was also tolerated (3v, 3w), providing a moderate yield (67\%). Notably, a fluzoxazone analogue was embedded in drug candidates in excellent yield (3x). Interestingly, medicinally useful carbazole was alkenylated to give the mono-olefinated product $3 \mathbf{y}$ in good yield.

We further investigated whether the protocol could be applied to a wide range of olefin coupling partners (Table 3). Methyl acrylate (2a), phosphonate (2b), styrene (2c), 3-fluorostyrene (2d) and phenyl vinyl sulfone (2e) were effectively coupled with $1 \mathbf{u}$ to furnish the corresponding products (3aa, 3ab, 3ac, 3ad and 3ae) in moderate to good yields (47-89\%), respectively. In addition, maleimide was also successfully coupled in moderate yield (3af). 
Table 2 Scope of olefinated tetrahydrocarbazoles ${ }^{a}$
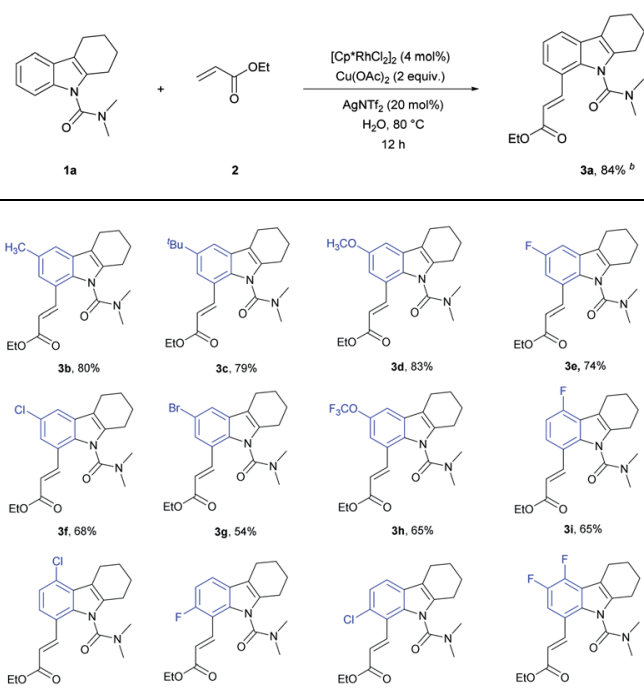

Eto<smiles>C1C[C@H]2CCC[C@@H]2C1</smiles>

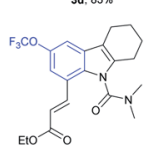

E10 $\mathrm{O}$

E10
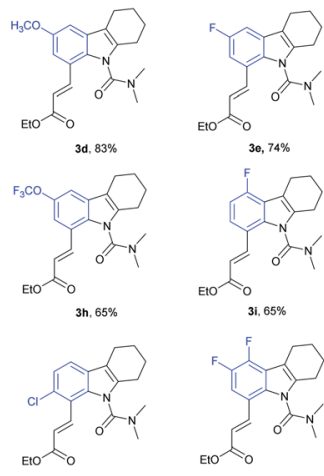

EtO

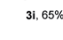

Eto E10

E10 $\aleph_{0}$

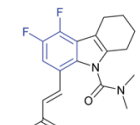

Eto
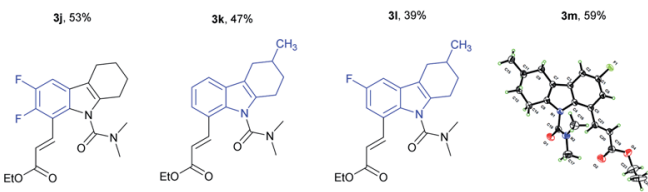

$3 n, 69 \%$

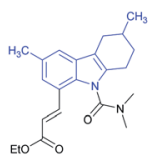

30, $83 \%$

Eto
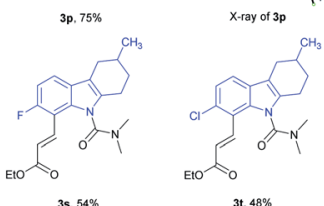

39.80\%

Eto $\aleph_{0}$

3s. $54 \%$

3.,

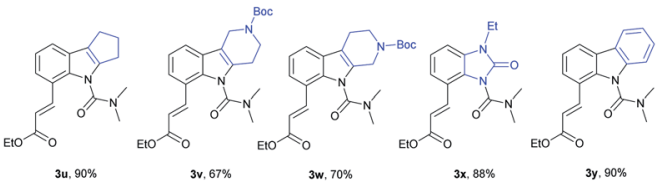

${ }^{a}$ 1a (0.1 mmol, 1 equiv.), 2 ( 2 equiv.), [Cp* $\left.\mathrm{RhCl}_{2}\right]_{2}$ ( $\left.4 \mathrm{~mol} \%\right), \mathrm{AgNTf}_{2}$ $(20 \mathrm{~mol} \%), \mathrm{Cu}(\mathrm{OAc})_{2}$ (2 equiv.), $\mathrm{H}_{2} \mathrm{O}(1.0 \mathrm{~mL}), 80{ }^{\circ} \mathrm{C}, 12$ h. ${ }^{b}$ Data are reported as isolated yields.

We have established a method for the olefination of tetrahydrocarbazole in water. This approach led us to explore whether this functionalization strategy could be applied for deuteration. We studied the selective deuteration process of tetrahydrocarbazole with substrate $\mathbf{1} \mathbf{u}$ as the initial substrate. On the basis of olefination conditions, different deuteriumcontaining solvents $\left(\mathrm{D}_{2} \mathrm{O},\left[\mathrm{D}_{4}\right]\right.$-methanol, [ $\left.\mathrm{D}_{1}\right]$-TFA, $\left.\mathrm{CDCl}_{3}\right)$ were tested (Table S6 in the ESI $\dagger$ ). ${ }^{19}$ To our delight, $1 \mathbf{u}$ was proceeded with $5 \mathrm{~mol} \%\left[\mathrm{Cp} * \mathrm{RhCl}_{2}\right]_{2}, 20 \mathrm{~mol} \% \mathrm{AgNTf}_{2}$, and 3 equiv. Of $\mathrm{Cu}(\mathrm{OAc})_{2}$, providing deuterated product $5 \mathbf{u}$ in $90 \%$ yield. This result was very meaningful as $\mathrm{D}_{2} \mathrm{O}$ acted as not only a deuterium provider, but the solvent of the reaction, and encouraged us to explore the utility of this method. Gratifyingly, most substrates were compatible, which greatly enhanced the scope of the method (Table 4). Under the reaction condition, the $\mathrm{CH}_{3}-, \mathrm{CH}_{3} \mathrm{O}_{-}^{-}, \mathrm{F}-, \mathrm{Cl}-$ and $\mathrm{Br}-$ substituted at the C6-position (5b, $\mathbf{5 d - 5 e , ~ 5 g ) ~ c o u l d ~ b e ~ s m o o t h l y ~ d e u t e r a t e d . ~ T h e ~ F - s u b s t i t u e n t ~ a t ~}$ C-5 (5i, 5n) had little influence on the results for the deuteration
Table 3 Scope of olefin coupling partners ${ }^{a, b}$
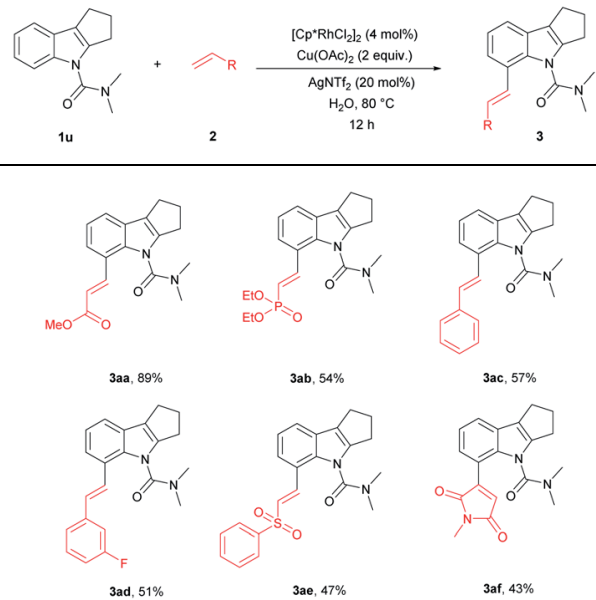

${ }^{a} \mathbf{1 u}\left(0.1 \mathrm{mmol}, 1 \text { equiv.), } 2 \text { (2 equiv.), [Cp* } \mathrm{RhCl}_{2}\right]_{2}$ (4 mol\%), $\operatorname{AgNTf}_{2}$ (20 mol\%), $\mathrm{Cu}(\mathrm{OAc})_{2}$ (2 equiv.), $\mathrm{H}_{2} \mathrm{O}(1.0 \mathrm{~mL}), 80{ }^{\circ} \mathrm{C}, 12 \mathrm{~h} .{ }^{b}$ Data are reported as isolated yields.

Table 4 Scope of tetrahydrocarbazole deuteration ${ }^{a}$
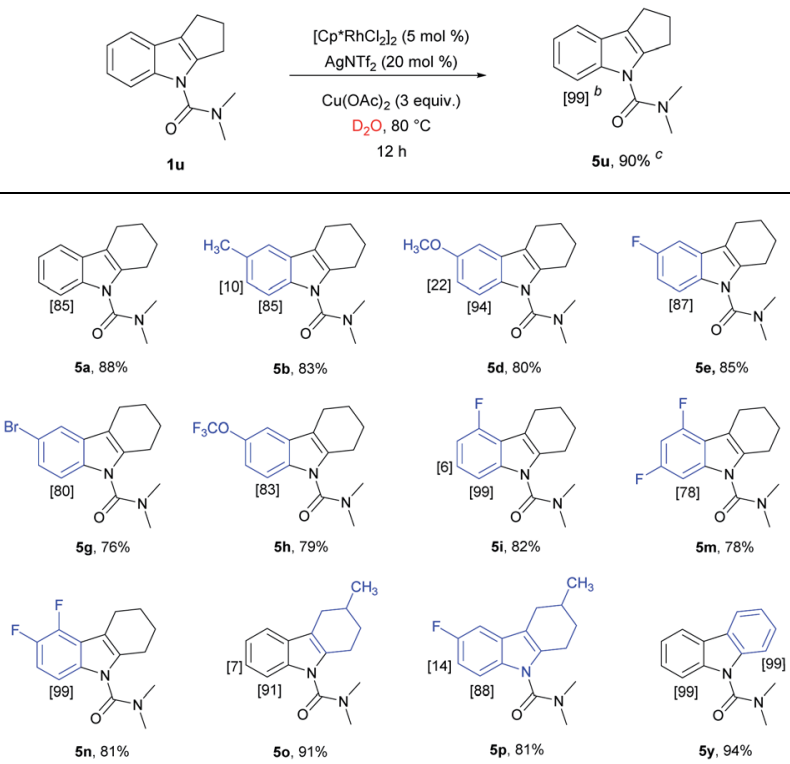

${ }^{a} 1 \mathbf{u}\left(0.1 \mathrm{mmol}, 1 \text { equiv.), [Cp* } \mathrm{RhCl}_{2}\right]_{2}$ (5 mol\%), $\operatorname{AgNTf}_{2}(20 \mathrm{~mol} \%)$, $\mathrm{Cu}(\mathrm{OAc})_{2} \quad\left(3\right.$ equiv.), $\mathrm{D}_{2} \mathrm{O}(0.5 \mathrm{~mL}), 80{ }^{\circ} \mathrm{C}, 12 \mathrm{~h} .{ }^{b}$ Deuterium incorporation at the aromatic position was determined by ${ }^{1} \mathrm{H}$ NMR spectroscopy. ${ }^{c}$ Data are reported as isolated yields.

rates and gave more than 99\% D incorporation. Carbazole was also shown to exhibit high levels of reactivity.

Next, the practicality of this protocol was examined. As shown in Scheme 2a, the reaction was scalable in normal reaction equipment and gave the olefinated products (52\% and $80 \%$ ) using water and DCE as solvent, respectively. Compounds 

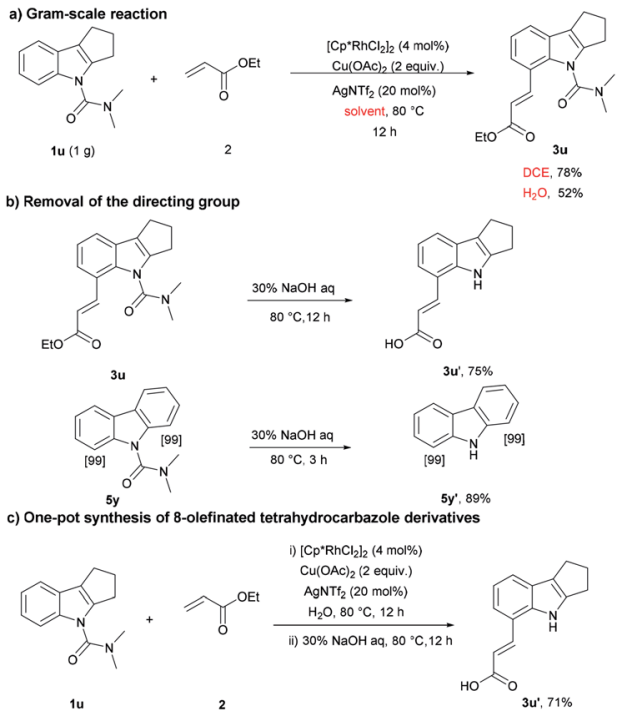

Scheme 2 The utility of this method.

3u and 5y were further deprotected under basic conditions to provide the corresponding products in $75 \%$ and $89 \%$ yield (Scheme 2b). In order to improve the synthetic utility of this protocol and avoid the tedious purification, we next pursued the direct synthesis of $3 \mathbf{u}^{\prime}$ by a one-pot method. Following rhodiumcatalyzed olefination, the product was filtered out through a celite pad without additional purification. Then, the directing group was removed, and the desired product $3 \mathbf{u}^{\prime}$ was obtained in $71 \%$ yield (Scheme 2c), which further demonstrated the applicability of the method.

An application of this novel methodology on the olefination of a more complex natural product evodiamine was tested (Scheme 3). The method was used to directly modify evodiamine and obtain evodiamine derivatives (4a-4d) with moderate yields.

To perceive the reaction mechanism, the following experiments were performed (Scheme 4). ${ }^{20}$ First, $N, N$-dimethylcarbamoyl-protected tetrahydrocarbazole $\mathbf{1 a}$ under the reaction condition with 10 equiv. of $\mathrm{D}_{2} \mathrm{O}$ gave a C8-deuterated compound in $60 \%$, indicating the reversibility of the $\mathrm{C}-\mathrm{H}$ activation step. Next, an intermolecular competition experiment between electronically diverse tetrahydrocarbazoles led to the conclusion that an electron-rich substrate tended to react at

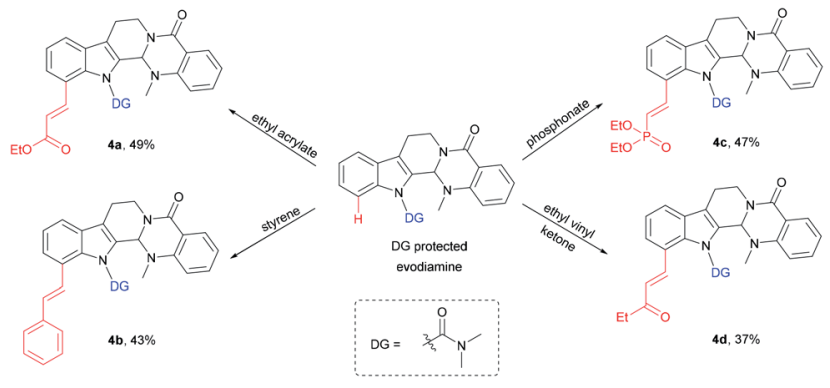

Scheme 3 Modification of natural product evodiamine.

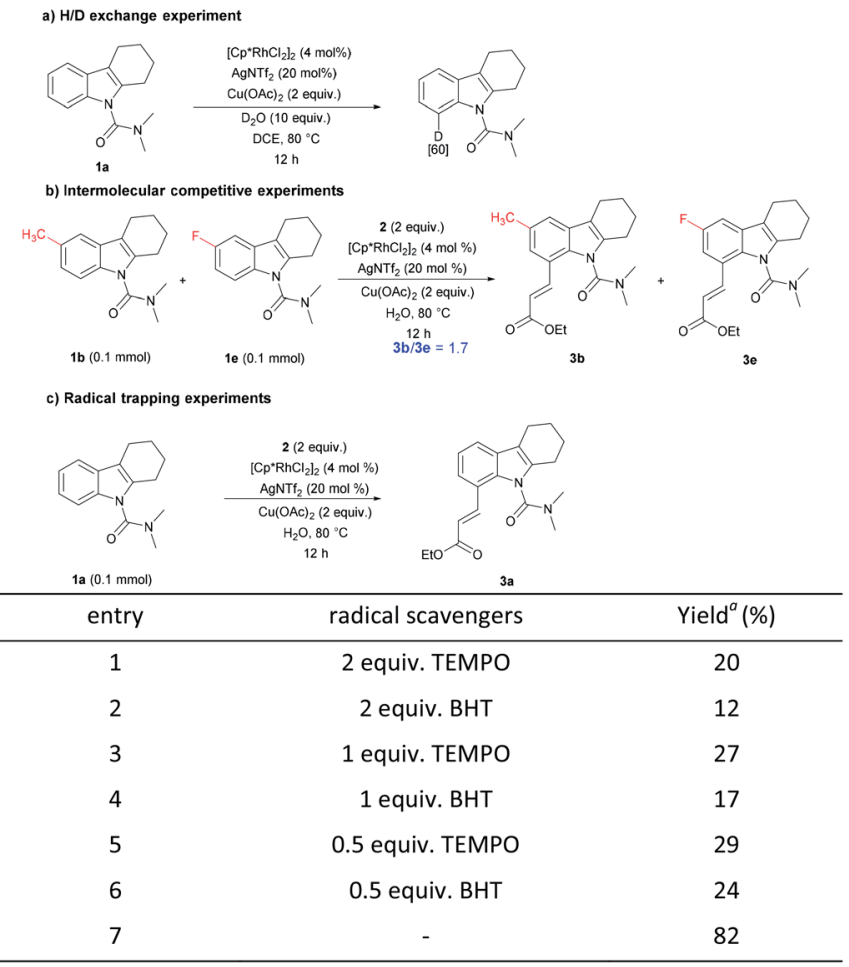

Scheme 4 Mechanistic studies. ${ }^{a}$ Data were obtained by ${ }^{1} \mathrm{H}$ NMR analysis with $\mathrm{CH}_{2} \mathrm{Br}_{2}$ as reference. $\mathrm{BHT}=2,6$-di-tert-butyl-4-methylphenol, TEMPO = 2,2,6,6-tetramethylpiperidinooxy.

a higher rate. Subsequently, radical trapping experiments were explored. The yield of the desired compound decreased remarkably with the addition of the radical scavengers. Adding different proportions of free radical scavenger had almost no obvious change, and the yield was similar to the variable without adding oxidant. These results suggest that a radical should not be involved in the reaction and the added radical scavengers may destroy the properties of the oxidant copper acetate.

To develop a better understanding of the catalyst reaction state, on-line ${ }^{1} \mathrm{H}$ NMR experiments were carried out (Fig. 1). There was a slight change in the peak position of the substrate

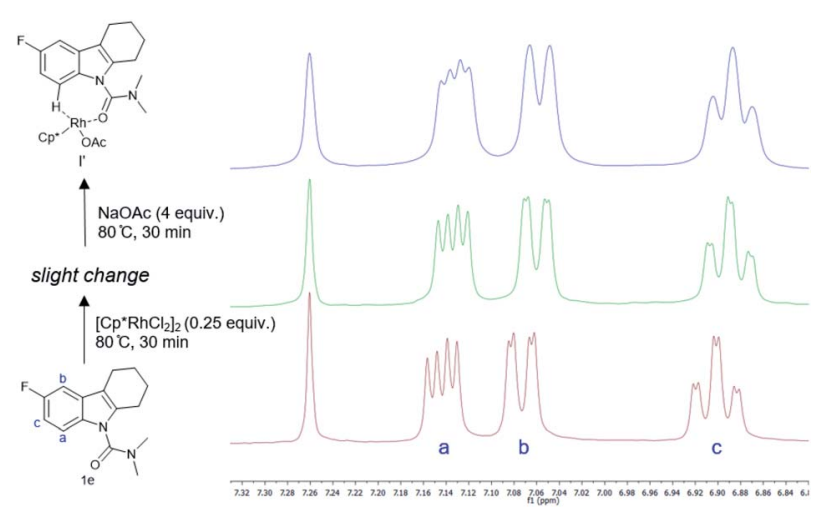

Fig. 1 Real-time on-line ${ }^{1} \mathrm{H}$ NMR monitoring of substrate-Rh-NaOAc interaction. 
after adding the catalyst $\left[\mathrm{Cp} * \mathrm{RhCl}_{2}\right]_{2}$. After adding sodium acetate, the peak shape of the substrate changed significantly. ${ }^{21 a, b}$ We speculate that the -OAc group promotes the weak coupling between the catalyst and the substrate, resulting in the change of the peak, producing the intermediate $\mathbf{I}^{\prime}$. These data indicated that intermediate $\mathbf{I}^{\prime}$ may be the reaction state of the catalyst in the system. Considering that C8-olefination could occur in DCE using $\mathrm{Ag}_{2} \mathrm{CO}_{3}$ as the oxidant, the reaction of $1 \mathrm{e}$ in $\mathrm{CDCl}_{3}$ was monitored with ${ }^{1} \mathrm{H}$ NMR spectroscopy. ${ }^{21 c, \boldsymbol{d}}$ The ${ }^{1} \mathrm{H}$ NMR analysis experiments were carried out in the same clean NMR tube in a continuous sequence. As shown in Fig. 2, the signals of $\mathbf{1 e}$ and 2 disappeared while that of product $3 \mathbf{e}$ increased with time. The reaction rate slowed down after $3.5 \mathrm{~h}$. The contrast spectra of $3 \mathbf{e}$ (top trace of Fig. 2) indicated nearly no byproduct formation.

Based on the above mechanistic studies and precedent literature, ${ }^{22}$ we have proposed a tentative catalytic cycle for this reaction (Scheme 5). We presume that, initially, a more active cationic rhodium complex $\mathbf{I}$ is formed with $\operatorname{AgNTf}_{2}$ and $\mathrm{Cu}(\mathrm{OAc})_{2}$, followed by the $\mathrm{C}-\mathrm{H}$ functionalization of substrate $\mathbf{1 u}$ to generate the six membered rhodacycle II. A subsequent olefin insertion step provides intermediate III. Then, rhodacycle III provides the eight-membered IV, which undergoes $\beta$-hydride elimination to continue the catalytic cycle and produces the desired olefinated product. Meanwhile, the $\mathrm{Rh}^{\mathrm{III}}$ complex regenerates $\mathrm{Rh}^{\mathrm{I}}$ by reoxidation, thereby completing the mechanistic cycle. Besides, the presence of intermediates (II and III or IV) was also detected by ESI-MS supporting the plausibility of our reaction hypothesis (see the ESI $\dagger$ ).
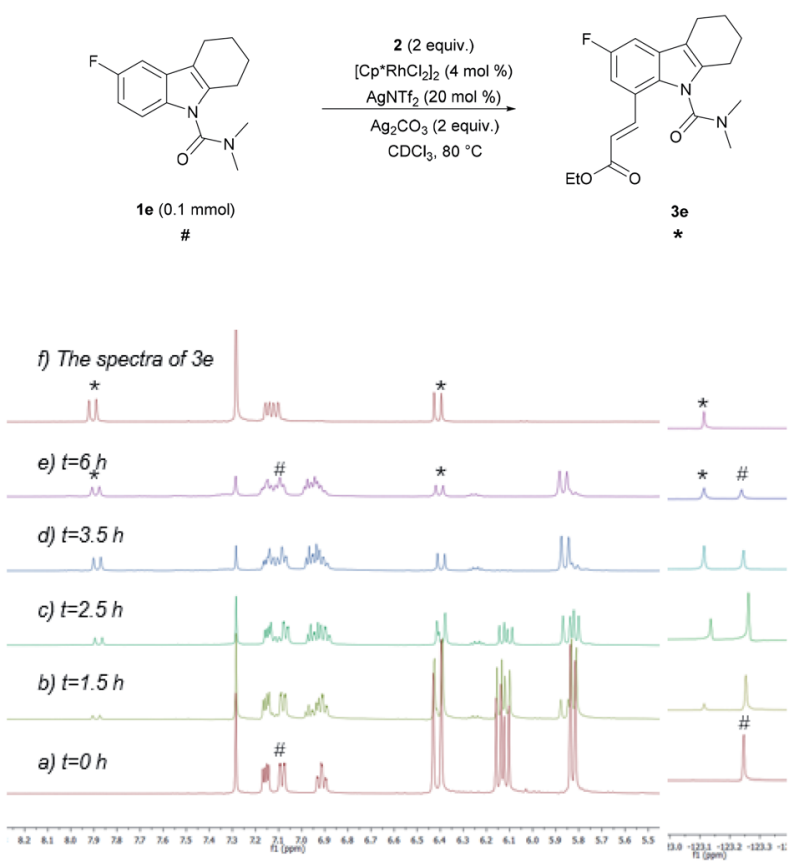

Fig. $2 \mathrm{C}-\mathrm{H}$ olefination monitored by ${ }^{1} \mathrm{H}$ NMR (left) and ${ }^{19} \mathrm{~F}$ NMR (right) spectroscopy. The spectrum (a) was acquired prior to heating, the spectrum (b) after heating for $1.5 \mathrm{~h}$, the spectrum (c) after heating for $2.5 \mathrm{~h}$, the spectrum (d) after heating for $3.5 \mathrm{~h}$ and the spectrum (e) after heating for $6 \mathrm{~h}$. *3e (product) peaks. ${ }^{*} 1 \mathrm{e}$ (reactant) peaks.

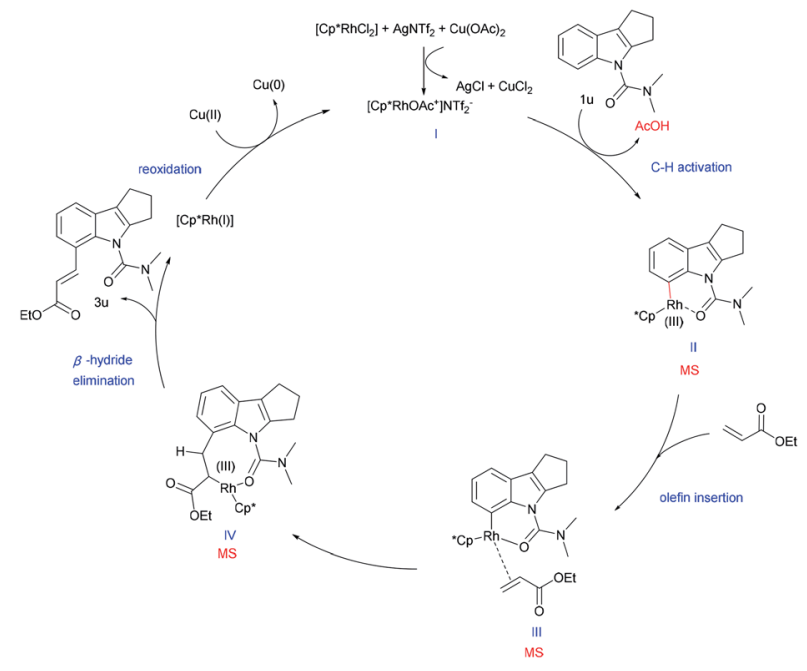

Scheme 5 A plausible mechanistic cycle.

\section{Conclusion}

In summary, we have reported an efficient, selective, direct olefination and deuteration of tetrahydrocarbazoles attached to the $N, N$-dimethylcarbamoyl-protected group by rhodium catalysis. Substitutions at various positions of the tetrahydrocarbazoles were tolerated. Easy removal of the template and gram-scale reaction demonstrate the extensive utility of this protocol. This method has been successfully applied to the natural product evodiamine. In this olefination reaction, water is an efficient solvent. The deuterium reaction uses $\mathrm{D}_{2} \mathrm{O}$, which is desirable and atom economical, as the deuterium source. Exclusive site selectivity, functional group tolerance, and latestage modifications are the important practical features. We believe that the new facile and green approach for modifying natural products could pave a new way in drug discovery.

\section{Conflicts of interest}

There are no conflicts to declare.

\section{Acknowledgements}

We are grateful for the support from the Natural Science Foundation of Jiangsu Province (Grants No BK20201332), the Six Talent Peaks Project of Jiangsu Province (Wang, X. B. SWYY107), Jiangsu Province '333' Project (Wang, X. B.), 111 Center from Ministry of Education of China and the State Administration of Foreign Experts Affairs of China (No: B18056), and the establishment and application of key technology system for obtaining and identifying effective/active small molecules of natural medicine (2017ZX09101003-001-007).

\section{Notes and references}

1 (a) L. Ackermann, Chem. Rev., 2011, 111, 1315; (b) S. Santoro, F. Ferlin, L. Luciani, L. Ackermann and L. Vaccaro, Green 
Chem., 2017, 19, 1601; (c) J. Chen, J. Xu, Y. Zhou, S. Xie, F. Gao, X. Xu, X. Xu and Z. Jin, Org. Lett., 2019, 21, 7928; (d) B. Wang, Y. Zhou, N. Xu, X. Xu, X. Xu and Z. Jin, Org. Lett., 2019, 21, 1885; (e) M. Shang, J. Z. Chan, M. Cao, Y. Chang, Q. Wang, B. Cook, S. Torker and M. Wasa, J. Am. Chem. Soc., 2018, 140, 10593; $(f)$ M. Shang, M. Cao, Q. Wang and M. Wasa, Angew. Chem., Int. Ed., 2017, 56, 13338; $(g)$ Z. Chen, B. Wang, J. Zhang, W. Yu, Z. Liu and Y. Zhang, Org. Chem. Front., 2015, 2, 1107.

2 (a) C. Gao, B. Li, X. Geng, Q. Zhou, X. Zhang and X. Fan, Green Chem., 2019, 21, 5113; (b) S. Guo, Y. Liu, L. Zhao, X. Zhang and X. Fan, Org. Lett., 2019, 21, 6437; (c) G. Song and X. Li, Acc. Chem. Res., 2015, 48, 1007; (d) H. Zhang, Z. Yang, J. Liu, X. Yu, Q. Wang and Y. Wu, Org. Chem. Front., 2019, 6, 967.

3 (a) J. S. Cannon and L. E. Overman, Angew. Chem., Int. Ed., 2012, 51, 4288; (b) G. Dong, C. Sheng, S. Wang, Z. Miao, J. Yao and W. Zhang, J. Med. Chem., 2010, 53, 7521; (c) S. K. Venkatesan and V. K. Dubey, Sci. World J., 2012, 963658; (d) X. Wang, J. You, J. B. King, D. R. Powell and R. H. Cichewicz, J. Nat. Prod., 2012, 75, 707.

4 Y. Nakano and D. W. Lupton, Chem. Commun., 2014, 50, 1757.

5 (a) J. A. Leitch, Y. Bhonoah and C. G. Frost, ACS Catal., 2017, 7, 5618; (b) T. A. Shah, P. B. De, S. Pradhan and T. Punniyamurthy, Chem. Commun., 2019, 55, 572; (c) Q. Wang, C. L. Zhi, P. P. Lu, S. Liu, X. Zhu, X. Q. Hao and M. P. Song, Adv. Synth. Catal., 2019, 361, 1253; (d) A. H. Sandtorv, Adv. Synth. Catal., 2015, 357, 2403.

6 (a) L. Xu, C. Zhang, Y. He, L. Tan and D. Ma, Angew. Chem., Int. Ed., 2016, 55, 321; (b) L. Xu, L. Tan and D. Ma, Synlett, 2017, 28, 2839; (c) B. Urones, R. G. Arrayas and J. C. Carretero, Org. Lett., 2013, 15, 1120; (d) X.-F. Yang, X.-H. Hu, C. Feng and T.-P. Loh, Chem. Commun., 2015, 51, 2532; (e) L. Guo, Y. Chen, R. Zhang, Q. Peng, L. Xu and X. Pan, Chem.-Asian J., 2017, 12, 289.

7 (a) X. Qiu, P. Wang, D. Wang, M. Wang, Y. Yuan and Z. Shi, Angew. Chem., Int. Ed., 2019, 58, 1504; (b) Y. Yang, X. Qiu, Y. Zhao, Y. Mu and Z. Shi, J. Am. Chem. Soc., 2016, 138, 495; (c) Y. Yang and Z. Shi, Chem. Commun., 2018, 54, 1676.

8 (a) A. J. Borah and Z. Shi, J. Am. Chem. Soc., 2018, 140, 6062; (b) X. Zhou, S. Yu, Z. Qi, L. Kong and X. Li, J. Org. Chem., 2016, 81, 4869.

9 (a) J. Lv, X. Chen, X.-S. Xue, B. Zhao, Y. Liang, M. Wang, L. Jin, Y. Yuan, Y. Han, Y. Zhao, Y. Lu, J. Zhao, W.-Y. Sun and K. N. Houk anorylation, Nature, 2019, 575, 336; (b) G. Chen, X. Zhang, R. Jia, B. Li and X. Fan, Adv. Synth. Catal., 2018, 360, 3781; (c) S. Guo, Y. Liu, X. Zhang and X. Fan, Adv. Synth. Catal., 2020, 362, 3011; (d) M. Chen, Y. Luo, C. Zhang, L. Guo, Q. Wang and Y. Wu, Org. Chem. Front., 2019, 6, 116; (e) Y. Kim, J. Park and S. Chang, Org. Lett., 2016, 18, 1892.

10 (a) L.-Y. Jiao, P. Smirnov and M. Oestreich, Org. Lett., 2014, 16, 6020; (b) L.-Y. Jiao and M. Oestreich, Chem.-Eur. J., 2013, 19, 10845.
11 (a) S. Fang, X. Wang, F. Yin, P. Cai, H. Yang and L. Kong, Org. Lett., 2019, 21, 1841; (b) P. Wang, P. Verma, G. Xia, J. Shi, J. X. Qiao, S. Tao, P. T. W. Cheng, M. A. Poss, M. E. Farmer, K. S. Yeung and J. Q. Yu, Nature, 2017, 551, 489; (c) D. S. Peters, F. E. Romesberg and P. S. Baran, J. Am. Chem. Soc., 2018, 140, 2072; (d) T. Patra, S. Bag, R. Kancherla, A. Mondal, A. Dey, S. Pimparkar, S. Agasti, A. Modak and D. Maiti, Angew. Chem., Int. Ed., 2016, 55, 7751.

12 (a) E. M. Simmons and J. F. Hartwig, Angew. Chem., Int. Ed., 2012, 51, 3066; (b) V. Soulard, G. Villa, D. P. Vollmar and P. Renaud, J. Am. Chem. Soc., 2017, 140, 155.

13 (a) Y. Y. Loh, K. Nagao, A. J. Hoover, D. Hesk, N. R. Rivera, S. L. Colletti, I. W. Davies and D. W. C. MacMillan, Science, 2017, 358, 1182; (b) Y. Zhang, M. D. Tortorella, Y. Wang, J. Liu, Z. Tu, X. Liu, Y. Bai, D. Wen, X. Lu, Y. Lu and J. J. Talley, ACS Med. Chem. Lett., 2014, 5, 1162; (c) Y. Zhu, J. Zhou and B. Jiao, ACS Med. Chem. Lett., 2013, 4, 349.

14 K. Inomata, A. Ohno, H. Tochio, S. Isogai, T. Tenno, I. Nakase, T. Takeuchi, S. Futaki, Y. Ito, H. Hiroaki and M. Shirakawa, Nature, 2009, 458, 106.

15 (a) K. Voronin, A. J. Allentoff, S. J. Bonacorsi Jr, C. Mapelli, S. X. Gong, V. Lee, D. Riexinger, N. Sanghvi, H. Jiang and J. Zeng, J. Labelled Compd. Radiopharm., 2014, 57, 579; (b) G. N. Nilsson and W. J. Kerr, J. Labelled Compd. Radiopharm., 2010, 53, 662; (c) J. Atzrodt and V. Derdau, J. Labelled Compd. Radiopharm., 2010, 53, 674.

16 C. Schmidt, Nat. Biotechnol., 2017, 35, 493.

17 (a) J. Atzrodt, V. Derdau, T. Fey and J. Zimmermann, Angew. Chem., Int. Ed., 2007, 46, 7744; (b) H. Jiang, S. Gao, J. Xu, X. Wu, A. Lin and H. Yao, Adv. Synth. Catal., 2016, 358, 188; (c) J. J. Tan, B. Liu and S. S. Su, Org. Chem. Front., 2018, 5, 3093; (d) M. S. Ledovskaya, K. S. Rodygin and V. P. Ananikov, Org. Chem. Front., 2018, 5, 226.

18 (a) Z. Song, R. Samanta and A. P. Antonchick, Org. Lett., 2013, 15, 5662; (b) H. Jiang, S. Gao, J. Xu, X. Wu, A. Lin and H. Yao, Adv. Synth. Catal., 2016, 358, 188.

19 S. Ma, G. Villa, P. S. Thuy-Boun, A. Homs and J. Q. Yu, Angew. Chem., Int. Ed., 2014, 53, 734.

20 (a) Z. Shi, M. Boultadakis-Arapinis and F. Glorius, Chem. Commun., 2013, 49, 6489; (b) Y. Qiu, W. J. Kong, J. Struwe, N. Sauermann, T. Rogge, A. Scheremetjew and L. Ackermann, Angew. Chem., Int. Ed., 2018, 57, 5828.

21 (a) X. Qi, Y. Li, R. Bai and Y. Lan, Acc. Chem. Res., 2017, 50, 2799; (b) A. I. VanderWeide, W. W. Brennessel and W. D. Jones, J. Org. Chem., 2019, 84, 12960; (c) A. K. Cook and M. S. Sanford, J. Am. Chem. Soc., 2015, 137, 3109; (d) M. Zhang, A. Luo, Y. Shi, R. Su, Y. Yang and J. You, ACS Catal., 2019, 9, 11802.

22 (a) S. Chen, M. Zhang, R. Su, X. Chen, B. Feng, Y. Yang and J. You, ACS Catal., 2019, 9, 6372; (b) S. K. Banjare, R. Chebolu and P. C. Ravikumar, Org. Lett., 2019, 21, 4049. 